\title{
How Social Factors Affect the Design of New Urban Residences
}

\author{
$\mathrm{Ke} \mathrm{Xie}^{1, \text { a }}$, Hui Shen ${ }^{2, \mathrm{~b}}$ \\ ${ }^{1}$ School of Architecture, North China University of Water Resources and Electric Power, Zhengzhou 450011, China \\ ${ }^{2}$ Henan Provincial Architectural Design Corporation, Zhengzhou 450003, China \\ a hicoco@yeah.net, ${ }^{\mathrm{b}}$ shenhui2084@126.com
}

\begin{abstract}
As an outcome of the society history, residential pattern must be affected by various factors. This paper is based on the basic requirement of residential housing, trying to carry out a multi-angle analysis of how social factors affect the design of new urban residences, and aims to dig out its internal law as well as enlightens the development of new residential pattern in the future.
\end{abstract}

Keywords-urban residences; social factors; life style; diversification.

\section{INTRODUCTION}

Residential housing is one of the basic means of subsistence which closely related to human survival and development, and an important symbol to judge the social economic development and people's living level. In the 21st century, with the adjustment of industrial structure, the social division of labor is increasingly refined, and the consumption demand is varied as well as concretized. Under the specific circumstance, not only the construction of urban housing has been well developed, but the quality of the buildings and the idea of developing have also been improved. Many new types of residential housing which aim to fit in with the needs of multiform life style have showed up and gradually gaining more and are important in the development of middle-class and high-class dwelling houses.

As an outcome of the society history, residential pattern must be affected by various factors. By analyzing those factors as well as digging out its internal law, we can have some new ideas to solve the problems that urban housing construction is facing with, exploring the trend of future evolution and so as to meet people's varied requirements of house form, and finally promoting the development of the construction of residential housing.

\section{RESIDENCE DEMAND}

The change of residence demand is the most important and direct cause of domestic residential housing reform. The change of house form is actually the external behavior of residence demand.

Psychology research shows that when the basic requirements were satisfied, people's requirements are tend to move to a higher level. Their spiritual demand will attracted more and more concern. In other words, people no longer merely regard dwelling as a "space" where can provide them living condition, but see dwelling as an important "environment" which influence people's growth. American humanistic psychologist Abraham Maslow pointed out that Physical Need, Safety Need, Love Need, Esteem Need and Self Actualization Need are the five different levels of people's need in his growth motivation theory. According to his theory, the five hierarchies of needs are arranged in order of priority just like steps. People will not pursue the needs of higher level until the more basic one is satisfied. The desire to increase the residential area, perfect the house type function; pay attention to the residential outdoor environment and landscape features; attach great importance to the residential security defensive and environmental protection, etc. show that the gradual change of living demand of the urban residents of China from quantity to quality is an explicit expression of this rule: Especially when these days our country is undergoing series of great historical social changes in economy, technology, institution and other fields, and it had a profound effect on people's living life. As Mo-tse said, "you seek for delicacies when you are well fed, you seek for finery when you keep warm, you seek for happiness when you live in quiet." Thus, it requires the architects to pay more attention on studying and analyzing the consumptive habit and the lifestyle of the users, then improve people's living habits by creating new forms of residences, and lead the new trend of development of housing.

\section{III.INTRAHOUSEHOLD FACTORS}

\section{A. Family Structure}

Family structure has a certain change regulation, although it has different forms in different countries. The birth of children and the independence of them (they start to live apart after marriage) the main clue of the change of the family structure. The current Chinese family structure mainly include single family, DINK family, nuclear family, stem family, joint family, etc., and the most common type is nuclear family. There are lots of singles and DINKs in the immigrant cities, since the mobility of the population has greatly increased.

The constant rising of the age at first marriage and age at first childbearing of urban youth has been a common social phenomenon. Although this kind of phenomenon is with periodic, (generally ranged from 1 to 5 years,) but their demands for the residential types should not be neglected. For example, the small apartment with two bedrooms and a 
living room shown in Fig. 1 is a residential type which those young people and the DINKs tend to chose.

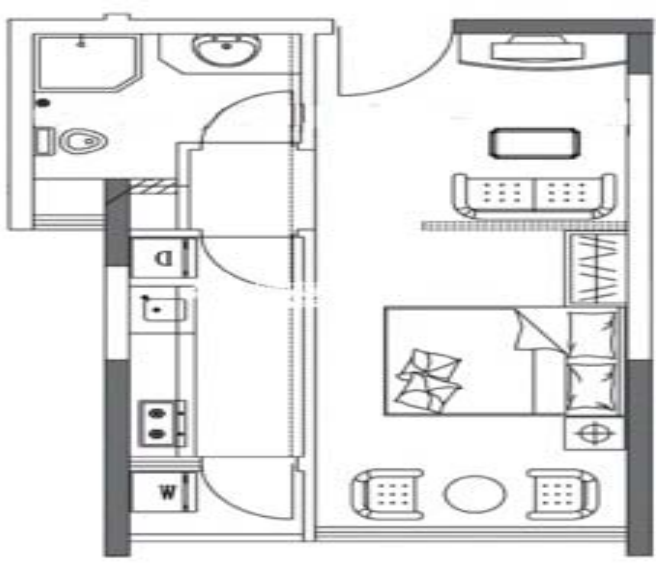

Figure 1. An apartment with two bedrooms anda living room

What's more, the present situation of population that our country stepped into aging society ahead of time has affected the urban residential pattern. An important cause of China's aging society intensifies is the one-child policy which was presented in the late 1970s. It only took our country 18 years (1981-1999) to become an aging society while it took the developed countries decades even more than 100 years, and in China the aging trend is still quickening . Domestic population growth and the change of the pattern will inevitably affect the current and future residential house type pattern. And it's a necessary problem about the future residential development.

\section{B. The Change of Household Life}

Since China's reform and opening up, people's ideas of market economy, competition concept, the talented person concept, information concept has gradually formed. As residents living from changed from simply having adequate food and clothing to well - off, household life also changed from autarky to market economy, from material to culture form, from the standard to the variety type, from closed to open. The change is mainly manifested in the following aspects:

Emphasize the comfort ,the rationality of the Residence and individuation of internal space

With the development of the society and common people's income increases, more and more people have the economic ability to buy their own houses. In the beginning stage of residential development in our country, a house with separated toilet, kitchen and living room could be regarded as a fully functioning one. But in today's society, people should live in a more intelligent space. Having several living spaces of different functions, such as separated dining room, living room, study, children room, etc., will be needed by more and more residents. And it's a trend of future residential development that the spaces can be decorated as the users wish.
1) The Change of Work Style Lead to the Change of Lifestyle

In the past, holding a position in the state - owned units is a ideal of many people.

The reform and opening-up and market economy changed people's mind since lifelong tenure changed to employment system. The words like "two-way selection", "job-hopping", "career change", and "crossover" has became buzzwords of a new era. With the coming of information age, both the development and progress of individuals need us to update knowledge constantly. Informationization makes people also want to read a lot in my spare time, reading the newspaper for self improvement. At the same time, the rapid expansion of the network makes the working place familial and miniaturized. Home office become a reality. Freelance writer, shop owners and private tailored workshop has become a new fashion of professional people. The change of work style inevitably lead to the change of lifestyle, and then affect the living pattern of people.

2) Some family function is gradually weakening while some new functions appears

With the development of economic, lots of modern household appliances have showed up in the ordinary people's homes. Manual operation has changed to automatic operation. Due to the increase in household income and the change of work style, many young people choose to dine out or order take-away food or fast food to solve the problem. For them, the function of the kitchen is weaker than ever before. The finished product and semi-manufactures showed up in the family kitchen, which has simplified the operation of equipment, and part of the space of the kitchen could be save .

Thus the arrangement of some functioning spaces in the house have changed. The open kitchen, for instance, is a form of it.

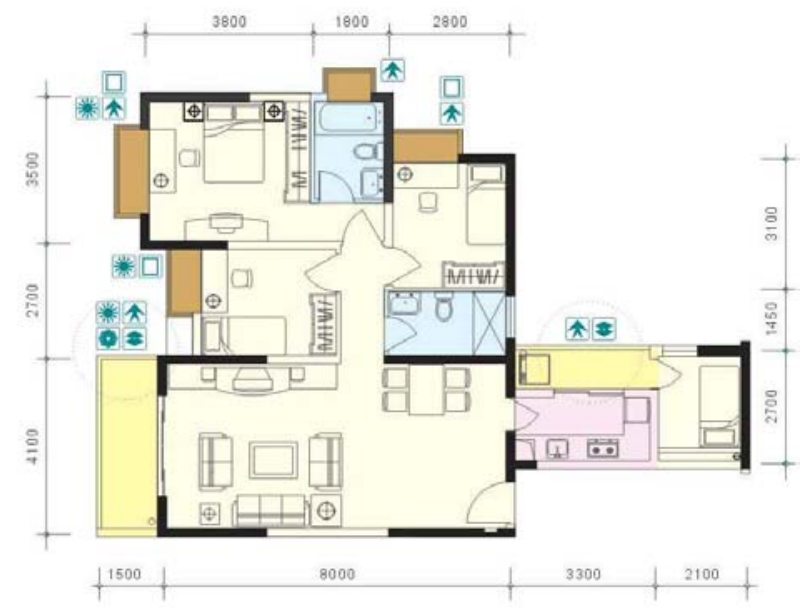

Figure 2. An apartment with 3 bedrooms and 2 living rooms + nanny room

In addition, the further development of domestic service industry prompted some housework gradually transferred to the society and become the forms of paid services, such as dry cleaners, semi-finished products processing, etc.; The appearance of month sister-in-law, hour maid and cleaning 
companies, also make employment service gradually into the families. This "into" a "out of" is changing the composition of the structure of house type, and it needs relatively independent space in the house. Therefore, as new functional spaces workers room, nanny room (figure 2) began to appear in the large houses.

\section{CONCLUSIONS}

In addition to the analyses above, there are many other factors affecting the design of dwelling house, such as economic factors. The division of economic capacity requires the market provide dwelling houses of different types and levels in order to meet the diversified housing demand. What's more, the improvement of new technology and material also provide new expression of the space. Take the LOFT as an example, without the support of architectural technology, it's impossible to separate rooms freely according to the needs of users with the large span and elevated storey height. Promotion of technology for the architectural design not only provides a new solution for building structure, but also inspires the architects to think about design in different ways.
To sum up, the social factors influence the new urban residential in all aspects, they are specific and real, and are they frequently change. Besides, there are some factors such as social customs, cultural factors, etc..The joint influence of these different factors are affecting urban residential development trend, which also play the role of inner motivation of the appearance of various new forms of residential. Market law determines the consumer's demand is always the market orientation. Architects should grasp the rules and understanding market trends accurately in order to design residences that obey the law of market and are popular with consumers.

\section{REFERENCES}

[1] Zhang Donghui, Wang Ning. The three-dimensional and layering living space[J]. Sichuan Building Science, 2005, 31(4): 106-108.

[2] Lisha Chang, Di Wu. Dwelling Ways of Youths and Humanity Design,. Housing Construction, 2003.(3):70-73.

[3] Lei Yang, The Study of Houses for the Youngs in City-Design for the Small-sized Apartment. Xi'an University of Architecture and Technology, 2004, pp. 80-82.

[4] Huang Nan, Shanxi Architecture, Rsearch on the Design of SOHO space, 2012(12),P17-18. 